\title{
The features and complexities of coincident deaths
}

\author{
Roger W. Byard
}

Accepted: 24 June 2014/Published online: 6 August 2014

(C) Springer Science+Business Media New York 2014

When two (or more) individuals are found unexpectedly deceased at the same location a number of scenarios are possible, ranging from accidents and natural diseases, to suicides or homicides. Accidents may result in multiple simultaneous fatalities from the actions of a lethal environmental agent. Examples include carbon monoxide leaking from a defective heating or cooking device in the home environment, or methane in industrial environments such as mines, wheat silos or sewers [1]. Double deaths have resulted from misadventures with illicit drugs, or in rare cases of sexual asphyxia. Disaster victim management exercises may be required for deaths from natural events such as earthquakes or tsunamis, or from accidents involving vehicle crashes or house fires [2].

The possibility of coincidental or related deaths from natural diseases must also be considered, particularly in the elderly. Examples of the latter include an elderly spouse who succumbs to ischemic heart disease while attempting to lift a dying partner back into bed, or ill or dependent persons who cannot fend for themselves once their carer dies. The dependent individual may succumb to an underlying illness, or may die of dehydration if he or she is either bedridden or too young to leave the house and seek help [3].

Once cases of multiple deaths that are clearly due to accidents or natural diseases have been excluded, this leaves the sometimes difficult issue of determining whether the fatalities may have involved murder, suicide or a combination of the two. While the percentage and types of

\section{R. W. Byard $(\square)$}

Discipline of Anatomy and Pathology, Level 3 Medical School North Building, School of Medical Sciences, The University of Adelaide, Frome Road, Adelaide 5005, Australia

e-mail: roger.byard@sa.gov.au cases vary among communities, double homicides, murdersuicides, so-called murder-accidents, or joint suicides are scenarios that must be considered. One of the most pressing issues is to quickly and correctly ascertain if either, or both, of the victims have been murdered, as this will necessitate coordinated and detailed crime scene and police investigations to try to identify the perpetrator(s). Clues to a double murder are often evidence of assault, theft, damage to the premises, absence of a weapon, and similar violent causes of death.

Murder-suicides, homicide-suicides or dyadic deaths refer to a situation where the perpetrator of a homicide has committed suicide after the death of the victim(s). While this usually occurs soon after the homicide, some authors have allowed up to 3 months between the events $[4,5]$. If there has been a delay between the two deaths clues to this at the scene may be that the bodies show different degrees of putrefaction, or possible tracking of blood by the perpetrator through the house or premises after the murder has occurred. A variety of classification systems have been proposed for murder-suicides. One that is commonly used is based on the type of victim-perpetrator relationship and possible motives or precipitating events, and includes categories involving a partner or spouse, other family members, or non-family members [6].

Spousal murder-suicides typically involve a male partner who kills because of "morbid jealousy" or jealous rage, or an elderly couple who are both suffering from significant illnesses, financial problems, and/or social isolation. The latter scenario overlaps with so-called "mercy killings" and suicide pacts. Other murder-suicides within a family involve a parent who murders their children and then commits suicide. There are often higher numbers of females involved in child murder-suicides, with the use of less violent methods than those of fathers. These consist of 
poisoning, suffocation, and carbon monoxide exposure, compared to shooting, strangling, and stabbing [7]. Suicide following infanticide is very uncommon. Another type of familial murder-suicide involves the killing of a dependent older child who may be suffering from significant physical or mental impairment, as the parent no longer feels capable of providing the necessary care due to age, illness, or financial problems.

Murder-suicides outside a family have achieved considerable media attention following school shootings in the United States. Although the reasons for these events are undoubtedly multifactorial, it would seem not unreasonable to postulate that ready access to firearms must facilitate these kinds of tragic and pointless shooting deaths. However, surprisingly this hypothesis has been argued against. Other extra-familial episodes involve disgruntled employees or ex-employees who seek vengeance for real or perceived insults or ill-handling, such as lack of promotion or failure of monetary payment for services. These types of events have been called "adversarial" murder-suicides. In the "pseudocommando" type of murder-suicide a range of firearms may be used that include semiautomatic weapons resulting in the deaths of a number of bystanders, or socalled "secondary targets". Murder-suicides occasionally occur in the setting of cults and in terrorist actions, such as the bombings in Bali in 2002. The latter have been called "kamikaze" murder-suicides, as the perpetrator dies as a result of the device or action that he or she has used to kill a large number of others [8]. On occasion the perpetrator of mass killings, often due to gunshot wounds, may subsequently deliberately expose himself to police gunfire in a suicidal "death by cop" action.

Murder-accident rather than murder-suicide is a term used for situations where a perpetrator has died while attempting to disguise a murder. A typical example involves a perpetrator being caught in a fire that has been deliberately started to confuse investigators by burning the victim's body and surroundings [9]. The different manner of death requires separation of murder-suicide from murder-accident as the psychological profile of the perpetrator is likely different in an accidental death due to miscalculation, rather than in an intentional death from a deliberate act.

Suicide pacts usually involve only two victims and are rare, accounting for only $0.6 \%$ of cases of suicide overall $[10,11]$. Decedents tend to be older, married, and from higher social classes. The sex ratio is equal, contrasting with a male: female ratio of $3: 1$ in single suicides [12]. Joint suicides have often been provoked by serious illness in one or both of the decedents and so a review of their recent medical histories may be illuminating. Suicide notes may be present, but not always [13], and the method used may not involve violence; i.e. drug overdose, or carbon monoxide exposure in a car, are preferred techniques [14]. The same non-violent method of death may be supportive of mutual consent. Although the family pet may also have been killed using a similar method, destruction of pets also occurs with violent murder-suicides by a "family annihilator" and so the coincident death of a pet may not be helpful. However, the degree of violence in the latter scenario usually helps to differentiate the two possibilities [15]. Problems may also arise in differentiating a suicide pact where a partner has been coerced to commit suicide, from a murder-suicide; possible suicide pacts between a parent and child may be, in reality, disguised murder-suicides. Similar issues may arise in cult deaths such as those encountered at Jonestown in Guyana [16].

As can be seen from the above discussion, finding more than one body at a scene necessitates the consideration of a wide variety of possible mechanisms and manners of death. Even when a homicide has occurred in one decedent, an accident, a suicide or a second homicide in the second decedent are all possibilities that require careful consideration. Assuming that double deaths are all murder-suicides may be counterproductive in terms of determining what events have led up to the fatalities, and what further investigative steps are required.

\section{References}

1. Byard RW, Wilson GW. Death scene gas analysis in suspected methane asphyxia. Am J Forensic Med Pathol. 1992;13:69-71.

2. Byard RW, Winskog C. Potential problems arising during international disaster victim identification exercises. Forensic Sci Med Pathol. 2010;6:1-2.

3. Byard RW. Incapacitation or death of a socially isolated parent or carer may result in the death of dependent children. J Paediatr Child Health. 2002;23:417-8.

4. Milroy CM. The epidemiology of homicide-suicide (dyadic death). Forensic Sci Int. 1995;71:117-22.

5. Felthous AR, Hempel A. Combined homicide-suicides: a review. J Forensic Sci. 1995;40:846-57.

6. Marzuk PM, Tardiff K, Hirsch CS. The epidemiology of murdersuicide. JAMA. 1992;267:3179-83.

7. Byard RW, Knight D, James RA, Gilbert J. Murder-suicides involving children - a 29 year study. Am J Forensic Med Pathol. 1999;20:323-7.

8. Byard RW. Murder-suicide—an overview. In: Tsokos M, editor. Forensic pathology reviews, vol. 3. Totowa, NJ: Humana Press; 2005. p. 337-47.

9. Byard RW, Veldhoen D, Kobus H, Heath K. 'Murder-suicide' or 'murder-accident'? Difficulties with the analysis of cases. J Forensic Sci. 2010;55:1375-7.

10. Brown M, Barraclough B. Partners in life and in death: the suicide pact in England and Wales 1988-1992. Psychol Med. 1999;29:1299-306.

11. Fishbain DA, Aldrich TE. Suicide pacts: international comparisons. J Clin Psychiatry. 1985;46:11-5. 
12. Austin AE, van den Heuvel C, Byard RW. Suicide in forensic practice-an Australian perspective. Aust J Forensic Sci. 2011;43:65-76.

13. Byard RW, Heath KJ. Suicide notes, age and the impact of suicide guides. Scand J Forensic Sci. 2007;13:10-1.

14. Byard RW, Hanson K, James RA, Gilbert JD. Suicide methods in the elderly in South Australia 1981-2000. J Clin Forensic Med. 2004;11:71-4.
15. Jensen LJ, Byard RW. Coincident deaths-double suicide or murder-suicide? Med Sci Law. 2009;49:27-32.

16. Thompson RL, Manders WW, Cowan WR. Postmortem findings of the victims of the Jonestown tragedy. J Forensic Sci. $1987 ; 32: 433-43$. 